\title{
SUPERVISÃO E DESENVOLVIMENTO PROFISSIONAL EM CONTEXTO DE ADD

\author{
Olhar crítico sobre o processo avaliativo de 2009/2011 na Escola Alfa
}

\author{
Maria Martins"
}

\begin{abstract}
Resumo: A avaliação do desempenho docente constitui uma prática social complexa e problemática, com repercussões na vida das escolas. Dos diversos modelos teóricos propostos, têm tomado terreno, a nível internacional, os que integram, complementarmente, uma dimensão formativa e desenvolvimentista e uma outra de caráter sumativo, com objetivos de diferenciação.

Neste trabalho, desenvolvido no âmbito do mestrado em Supervisão Pedagógica e Avaliação de Docentes na Universidade Católica, é feita, em primeiro lugar, uma análise a essa problemática com base na literatura da especialidade e na produção normativa em Portugal. É também apresentada uma reflexão crítica do processo avaliativo de 2009/2011 numa escola básica dos $2^{\circ}$ e $3^{\circ}$ ciclos. Os dados, recolhidos através da aplicação de entrevista a três docentes dessa escola, permitem identificar algumas infidelidades em relação aos referenciais (internos e externos), mas sobretudo, um desvio substancial face aos modelos teóricos propostos pela literatura.

Com base na identificação de alguns pontos menos conseguidos, $e$ tendo como referência esses mesmos modelos, são adiantadas algumas propostas que poderão contribuir para a melhoria do processo.
\end{abstract}

Palavras-Chave: Avaliação; Supervisão; Observação; Desenvolvimento Profissional e Organizacional

\begin{abstract}
The teacher performance evaluation is a complex and problematic social practice, affecting the lives of schools. From a various range of theoretical models, the ones which, for purposes of differentiation, combine a formative and developmental dimension with one of summative assessment have taken ground internationally.
\end{abstract}

\footnotetext{
* Docente do Ensino Básico. Especialização em Supervisão Pedagógica e Avaliação do Desempenho Docente. Mestre em Administração e Organização Escolar, Doutora em Ciências da Educação: mariamartinssousa@gmail.com
} 
In this work, developed within the master's degree in Supervision and Evaluation of Teachers, in Universidade Católica, we firstly lead an analysis of this issue based on the literature and the Portuguese legislation. We also present a critical analysis of the assessment process for 2009/2011 performed in an elementary school. The data, based on the application of interviews conducted on three teachers of the school, identify some infidelities in relation to the references (internal and external) but above all, a substantial variance compared to the theoretical models proposed in the literature. Based on the identification of some unreached aspects, and taking as reference these same models, some proposals which can contribute to improve the process are brought up.

Keywords: Evaluation; Supervision; Observation, Professional and Organizational Development.

\section{INTRODUÇÃO}

\subsection{A problemática da avaliação de desempenho docente: emergência e desenvolvimento}

Na história da educação sempre esteve inscrita a preocupação com a eficácia das escolas e dos sistemas educativos. Contudo, a crença de que a mudança dos currículos/programas e das organizações escolares era condição suficiente para a melhoria dos sistemas educativos fez com que, durante décadas, por todo o mundo, não se colocasse o enfoque no desenvolvimento profissional dos professores, pelo que a sua avaliação não era considerada uma prioridade (Fernandes, 2008:11), até que um dia (anos 70) descobrimos que também há dificuldades de ensino (Leite et al, 1995:32). Curado (2002: 70-71), numa perspetiva histórica, lembra os primeiros ensaios de $\mathrm{ADD}^{\dagger}$ Inglaterra, finais do séc. XIX e EUA, início do séc. XX -, prática que tem vindo a conhecer uma acentuada visibilidade nas últimas três décadas, recebendo uma atenção crescente por parte de investigadores, professores e decisores políticos um pouco por todo o mundo (Flores, 2010:7). Com efeito, num quadro global de racionalização de recursos e a necessária prestação de contas, associada ao paradigma da qualidade, assiste-se a um movimento no sentido de uma exigência crescente relativamente à eficácia das organizações, mais acentuadamente a partir dos anos 90 do séc. XX. Em matéria de educação, essa exigência de qualidade e eficiência dos sistemas educativos, através da melhoria das práticas de ensino e do desenvolvimento profissional dos professores, com impacto positivo na melhoria das aprendizagens dos alunos, tem-se traduzido em medidas de política educativa conducentes a um maior controlo e monitorização do desempenho e da eficácia da organização

\footnotetext{
${ }^{\dagger}$ Avaliação de Desempenho Docente
} 
escolar, nomeadamente através da implementação de sistemas de avaliação do desempenho dos professores.

\subsection{Uma visão triangular do processo de ADD}

A avaliação, relativamente recente enquanto disciplina, é um domínio científico e uma prática social cada vez mais essencial para compreender um contexto e nele intervir, nomeadamente na área da educação, enquanto estratégia ao serviço da melhoria da qualidade dos professores, das escolas e dos sistemas de ensino. No entanto, a experimentação de uma variedade de modelos tem mostrado que a ADD, sendo reconhecidamente essencial para a melhoria dos sistemas educativos, é um construto social complexo e problemático, que cria muita turbulência e conflitos no ambiente escolar, afetando as suas dinâmicas e à volta do qual existe um dissenso generalizado (Pacheco, 2009: 43). Essa complexidade e falta de consenso (Flores, 2010:7) advêm, segundo Fernandes (2008:5), do facto de se estar em presença de questões éticas, sociais e políticas difíceis de contornar e explicam, na opinião de Caetano (2008: 8), o facto de continuar por estabelecer a sua robustez, passados cem anos sobre a primeira aplicação a nível das organizações.

Para além da diversidade de intervenientes, com características e motivações próprias, dois fatores contribuem largamente para esta complexidade e explicam a existência de uma diversidade de abordagens e modelos. Em primeiro lugar, os pressupostos subjacentes a cada modelo de avaliação, isto é, as questões teóricas que o fundamentam. As conceções e visões do mundo, de escola, de aprendizagem e de ensino que o sustentam. Dos valores e da ética que o orientam. E das políticas que o motivam (Fernandes, 2008:4) e nele são impressos. Estas perspetivas teóricas e filosóficas sobre o que é um ensino de qualidade têm subjacente um tipo de trabalho pedagógico a privilegiar na escola, bem como o desempenho que deve ter um bom professor e determinam os fins a que se destina o conjunto de informações recolhidas e as tomadas de decisão que advêm dos juízos de valor formulados, isto é, as finalidades ou propósitos da avaliação. Assim, os modelos de avaliação do desempenho docente podem ser orientados por critérios, tidos como referência e em relação aos quais é feita a comparação (avaliação criterial); podem ser baseados em objetivos (do sistema, da organização escola, individuais), cujo grau de consecução é tido em conta no momento do juízo avaliativo e podem, ainda, corresponder a processos burocráticos e hierarquizados ou de pendor mais democrático e deliberativo.

Estes dois fatores são determinantes na conceção, elaboração e implementação do modelo de avaliação e deles decorrem os procedimentos a desenvolver: as fontes de informação e a metodologia utilizada na sua recolha, agregação, análise e interpretação, nomeadamente o instrumentário; os timings e a periodicidade; os intervenientes no processo; a natureza das 
relações de poder entre avaliado e avaliador; o tipo de juízo a formular e o grau de formalidade de todo o processo. Esta relação triangular entre os elementos constitutivos de qualquer processo avaliativo, pode ser representada através da estrutura esquemática que se segue (fig.1).

\section{Figura I}

Relação triangular dos elementos constitutivos do processo de ADD: a trilogia dos Ps

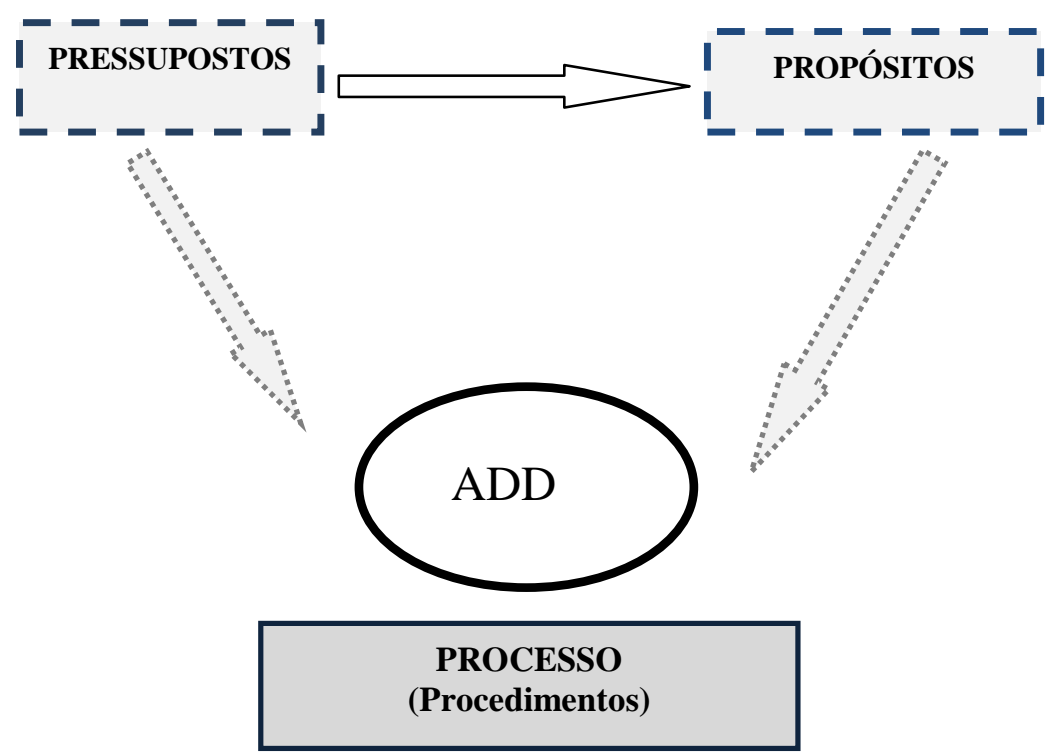

Esquema construído pela autora

Desta relação podem decorrer modelos de avaliação mais orientados para a seleção (de ingresso ou progressão) e prestação pública de contas, consubstanciando uma avaliação de pendor mais formal e sumativo, ou, contrariamente e numa conceção mais profissional da função docente, dar origem a formatos cujo enfoque é o desenvolvimento pessoal e profissional dos professores, enquanto condição central para a melhoria da qualidade do ensino e das aprendizagens, correspondendo a sistemas avaliativos de caráter mais formativo-reflexivo, nomeadamente, através de processos de supervisão para a autonomia e emancipação docente. De sublinhar que, entre as várias lógicas que podem enformar qualquer modelo de avaliação, estas duas têm vindo a tomar terreno, em matéria de avaliação de professores, um pouco por todo o mundo. 


\subsection{ADD em Portugal: normatividade e (des)construção das práticas}

Os primeiros registos sobre esta matéria em Portugal referem uma avaliação feita pelos reitores (Circular $n^{\circ}$ 367/32, de 11 de Março), coadjuvados pela inspeção a partir de 1947 (D.L. no 36507, de 17 de setembro) e até 1974. Numa perspetiva do ensino como trabalho (Fernandes, 2008: 17) e consubstanciando uma visão racionalista e burocrática da ADD (id.: 21), o enfoque era o desempenho do professor, não numa perspetiva profissional da função docente (Formosinho, Machado \& OliveiraFormosinho, 2010:79), mas como garante da sua conformidade ao regime político vigente. De 1974 a 1986, e por imperativos de urgência em recrutar e qualificar um número significativo de docentes, o movimento de reforma educativa focaliza-se na formação inicial dos mesmos, pelo que a sua avaliação desaparece da agenda educativa (Curado, 2002:16), emergindo a primeira política de ADD em finais dos anos 80, com a publicação da LBSE

No seguimento da mesma, e com a publicação do DL n $139-\mathrm{A} / 90$, de 28 de abril $\left(1^{\circ} \mathrm{ECD}\right)^{\S}$, é estabelecida, pela primeira vez, a ligação da $\mathrm{ADD}$ à progressão na carreira. Considerando o desenvolvimento profissional como essencial para a melhoria do ensino, este normativo institui, além da antiguidade, a obrigatoriedade de formação contínua como requisito para essa progressão. O avaliado é corresponsabilizado no processo, através da obrigatoriedade de apresentação de um relatório de autoavaliação.

Em finais dos anos 90 é reformulada a política de ADD, pelo DL $\mathrm{n}^{\circ}$ 11/98, de 15 de Maio. Refletindo o movimento a favor do aumento do poder dos professores, este normativo institui a avaliação por pares, atribuindo a apreciação do relatório de autoavaliação a uma comissão de professores. Em 2008, agora num quadro internacional de políticas educativas que colocam a ênfase na necessidade de promoção do sucesso escolar, e num contexto em que a discussão se centrava já no modelo a implementar, é reformulada a política de ADD, pela publicação do DL n ${ }^{\circ} 15 / 2007^{* *}$, de 19 de janeiro. Este normativo, (que introduz a divisão da carreira em professor e professor titular), estabelecendo como referentes internos os objetivos do PE e PCT e os indicadores de medida (resultados dos alunos,...), centra a avaliação docente na escola e institui um modelo baseado no reconhecimento do mérito e excelência, bem como no incentivo à formação, sendo reforçada a avaliação por pares, que passa a ser da responsabilidade do Coordenador de Departamento. Este modelo, teoricamente mais centrado no produto -

\footnotetext{
* Lei $n^{\circ} 46 / 86$, de 14 de outubro (posteriormente alterada pelas Leis $n^{\text {os }} 115 / 97$, de 19 de setembro e 49/2005, 30 de agosto) que aponta já, no ponto dois do seu artigo $36^{\circ}$, que a progressão na carreira deve estar ligada à avaliação de toda a atividade desenvolvida, individualmente ou em grupo, na instituição educativa,...

${ }^{\S}$ Regulamentado pelo DR $n^{\circ} 14 / 92$, de 4 de junho

** Regulamentada pelo DR n ${ }^{\circ} 2 / 2008$, de 10 de janeiro
} 
objetivos e resultados (Fernandes, 2008: 21) - viria a ser implementado apenas no primeiro ciclo avaliativo 2007/2009 e numa versão simplificada que exclui os resultados dos alunos como critério de avaliação dos professores.

O processo de ADD do período 2009-2011: Decorrente do sentimento de contestação generalizada e das enormes pressões emanadas de diversas instâncias, após o ciclo avaliativo de 2007/2009, e tendo como referência reivindicativa o memorando de entendimento firmado entre o $\mathrm{ME}$ e as estruturas sindicais, o DL n ${ }^{\circ} 75 / 2010$ (11 ${ }^{\text {a }}$ versão do $\left.\mathrm{ECD}\right)$, regulamentado pelo $\mathrm{DR} \mathrm{n}^{\circ}$ 2/2010, ambos de 23 de junho, põe fim à divisão da carreira e introduz alterações que reforçam a articulação entre a ADD e a progressão na carreira, através de mecanismos que premeiam o mérito e a excelência. É igualmente reforçada a importância da supervisão pedagógica, como forma de garantir a qualidade do serviço educativo (Graça, et al, 2011:35). A ADD passa a ter como referentes os padrões de desempenho docente estabelecidos a nível nacional, os objetivos e metas fixados no PE e os objetivos individuais (facultativos). Sendo a ADD da competência do júri de avaliação (presidido pelo Diretor e constituído pela $\mathrm{CCAD}^{\dagger \dagger}$ e pelo relator), é reforçada a avaliação por pares, através do relator. Este é o elemento do júri que, através de um processo supervisivo de caráter formativo, tem a responsabilidade de acompanhar o trabalho do professor ao longo do período avaliativo (inclusive de observação de aulas, se requisitadas pelo avaliado) e de apresentar uma proposta de avaliação final, mantendo com aquele uma interação permanente, potenciando a dimensão formativa da avaliação $\left(\operatorname{art}^{\circ}\right.$ 14, DR $\mathrm{n}^{\circ}$ 2/2010, de 23 de junho), através da emancipação do avaliado (Vieira \& Moreira, 2011).

O professor avaliado, continua a ser chamado a tomar posição relativamente ao seu desempenho, através da elaboração e apresentação de um relatório de autoavaliação, que faz parte dos documentos de avaliação, a par da ficha de avaliação global (apresentada ao júri pelo relator e que inclui uma proposta de avaliação) e do registo de observação de aulas, se existir.

Trata-se de um modelo teórica e discursivamente assumido como valorizando fundamentalmente o processo, pelo proposto enfoque no desenvolvimento profissional contextualizado e no sentido da melhoria do ensino (ponto $3, \operatorname{art}^{\circ} 40^{\circ}$ do DL 75/2010). No entanto, a observação de aulas, ao ser facultativa, não é perspetivada como uma estratégia fundamental no processo de ADD, o que mostra a pouca importância atribuída ao processo de supervisão acompanhada. Assim, não deixou de ser essencialmente um modelo de produto, uma vez que tem como finalidade escrutinar e medir $o$ desempenho e a eficácia dos professores (Fernandes, 2008: 20). Na prática, este viria a ser, aliás, o grande enfoque de todo o processo, o que constituiu

\footnotetext{
${ }^{\dagger \dagger}$ Comissão de Coordenação da Avaliação Docente (D R nº2/2010, de 23 de janeiro, $\left.\operatorname{art}^{\mathrm{o}} 12^{\circ}\right)$
} 
matéria de descontentamento generalizado e de mal-estar no seio da classe docente.

\section{SUPERVISÃO EM CONTEXTO DE ADD}

\subsection{Supervisionar para melhorar: do controlo à emancipação}

Em matéria de Educação, Ramos (2007:11) chama a atenção para a crescente visibilidade da temática da ADD pelo interesse que tem suscitado, não só ao poder político, mas também à comunidade científica e investigadora e à sociedade em geral. Acrescenta a mesma autora não existirem dúvidas relativamente à importância estratégica que a avaliação passou a assumir nos processos de desenvolvimento dos sistemas de educação.

É neste contexto que a avaliação de professores aparece associada, na legislação e na literatura, a processos de supervisão, assistindo-se a uma diversificação das funções da avaliação e das expetativas que sobre ela recaem. Avaliação e supervisão são habitualmente apresentadas como indissociáveis e complementares, dada a dupla função cometida atualmente à primeira: promoção do desenvolvimento profissional dos professores (perspetiva subjetiva e desenvolvimentista) e reunir evidências sobre o mérito para regular a progressão na carreira (perspetiva sumativa, positivista, de prestação de contas). Em sentido inverso vai a opinião de Vieira e Moreira que consideram estes dois propósitos absolutamente inconciliáveis. Questionando o anunciado potencial transformador e emancipador da avaliação e da supervisão quando as mesmas têm cumulativamente o papel de controlo e seriação (2011: 8), defendem as autoras que para a consecução de finalidades diferentes devem ser construídos modelos diferentes de avaliação docente (id.: 61).

Contudo, a supervisão, enquanto processo de regulação das práticas de ensino e de aprendizagem, corresponde a uma estratégia indissociável da atividade pedagógica e, por conseguinte, da atividade avaliativa do desempenho docente. Alarcão e Tavares (2003: 16), numa revisão diacrónica do conceito de supervisão, que evoluiu nas últimas décadas de uma visão de mero controlo e fiscalização para uma conceção de acompanhamento formativo, definem-na como o processo em que um professor, supostamente mais experiente e mais informado orienta outro professor, no sentido do seu desenvolvimento profissional e pessoal. Na mesma linha, Vieira e Moreira (2011: 9), chamando a atenção para o facto de as potencialidades da supervisão e avaliação se jogarem no espaço das possibilidades, defendem a importância capital que representa a apropriação destes processos, por parte dos professores, como estratégias de (auto)crítica, desocultação de constrangimentos e reconstrução individual e coletiva da profissionalidade docente, ao serviço de uma educação transformadora e emancipatória, 
considerando esta a única forma de mudar o tradicional pendor burocrático, mecanizado e conservador de mero controlo e subjugação.

Neste sentido, Vieira (1993:91), considera crucial o papel do supervisor, a quem atribui como função fundamental o desenvolvimento da autonomia do supervisionado em relação ao desenho e construção do seu projeto de desenvolvimento profissional e da sua proatividade face a todo o processo de supervisão. Deste ponto de vista, o professor deve ter uma postura autosupervisiva, reflexiva e indagatória sobre a sua prática pedagógica. Deve ser capaz de, com humildade, reconhecer as suas fragilidades profissionais e, com firmeza, assumi-las como ponto de partida para a re(des)construção das mesmas, a partir de uma perspetiva autocrítica e autonomamente desenvolvimentista, como lembram abundantemente Vieira e Moreira (2011). No seu conjunto, e para que todos, e cada um, possam concorrer para o desenvolvimento da organização, é igualmente importante o desenvolvimento de uma cultura de trabalho em equipa, com base em práticas de colaboração e heterosupervisão, em que as boas experiências sejam partilhadas e replicadas ao todo que é a escola - desejavelmente uma comunidade aprendente e onde os professores aprendem (Graça et al, 2011: 62).

Vieira e Moreira (2011:11), fazendo a apologia das potencialidades duma cultura supervisiva e autosupervisiva, e numa perspetiva de pedagogia para a autonomia (de professores e alunos), defendem mesmo que uma pedagogia sem supervisão será menos pedagógica. Contudo, estas autoras apresentam várias formas de desenvolvimento do processo de supervisão (2011: 15-17).

A partir dos estudos realizados por Glickman e colaboradores (2004), e colocando a tónica nos discursos do supervisor, consideram a existência de três estilos supervisivos, a que correspondem diferentes funções do supervisor e diferentes graus de controlo deste sobre as decisões e ações do professor supervisionado: não diretivo, colaborativo e diretivo. Alertando para a inconveniência do último estilo, em sede de ADD, e numa situação de supervisão entre pares - o supervisor colega, como lhe chamam Alarcão \& Tavares (2003: 113) - as autoras consideram ser recomendável o estilo não diretivo, cujas funções passam sobretudo pela atenção a prestar ao professor, pela clarificação, pelo encorajamento e ainda servir de exemplo, muito mais do que orientar, dirigir ou condicionar.

Denotando igual preocupação, Graça et al (2011: 56) lembram que um modelo de supervisão em que o poder de decisão esteja todo do lado do supervisor trará fraco contributo para uma avaliação que se pretende baseada numa cultura de partilha, colaboração e abertura à inovação para a melhoria, assente em relações profissionais de confiança, credibilidade e respeito. Só assim, a supervisão consubstancia uma estratégia potenciadora do crescimento pessoal e profissional, através da complementaridade da reflexão na ação, reflexão sobre a ação e reflexão sobre a reflexão da ação (id.: 62). A reflexividade, enquanto prática necessariamente permanente na atividade do professor e autorregulação crítica da sua ação, é apresentada por Vieira e Moreira (2011: 14) como inerente à sua atividade pedagógica, não 
decorrendo, por conseguinte, da avaliação do desempenho. Estas autoras sublinham o facto de essa atitude de permanente reflexividade ser o denominador comum a todas as propostas de modelos teóricos e metodológicos de supervisão apresentados. Na mesma linha de pensamento, Baptista (2011:31), numa análise da ética profissional e organizacional em contexto de avaliação de desempenho, considera constituir esta uma preciosa oportunidade de desocultação e de discussão dos valores profissionais, preconizando igualmente, que a mesma, entre outras, representa uma oportunidade privilegiada de reflexão sobre as práticas educativas, de explicitação deontológica e de estímulo ao desenvolvimento profissional.

Face ao impacto da estratégia do supervisor no processo, lembram Vieira e Moreira (2011: 15-17) que o professor supervisionado pode fazer toda a diferença, dependendo da sua autonomia e capacidade para tomar decisões. Nesta perspetiva, e citando Waite (1995), as diferentes formas de exercício do poder na interação supervisiva continuam a depender da maior ou menor flexibilidade da agenda do supervisor, contudo, a tónica é colocada também no papel desempenhado pelo professor, que pode ir de uma atitude passiva, a uma posição colaborativa ou, pelo contrário, assumir um papel adversativo e opositor. Convocando ainda este autor, apresentam o conceito de supervisor situacional, considerado relevante em contexto de ADD. Este estilo de supervisão prevê e implica que o supervisor, conhecendo bem o contexto, promova a sua desconstrução e melhoria, através de estratégias de diálogo crítico, democrático e construtivo, que contrariem as práticas tradicionais burocráticas, ritualizadas e de acentuação das assimetrias de poder e de decisão.

Fazendo a apologia da necessidade do desenvolvimento de relações de colegialidade entre supervisor $\mathrm{e}$ professor para a promoção do desenvolvimento profissional, apresentam, ainda, a visão de Blase e Blase (1995), que conclui nos seus estudos ser indispensável num processo supervisivo a tomada em consideração das orientações pessoais do professor, o desenvolvimento de uma comunicação clara e explicitação mútua, bem como uma permanente negociação a partir de fontes de informação comuns a supervisor e supervisionado, que possibilite a construção de referenciais e de uma linguagem comuns.

Do mesmo modo, e por considerarem o ensino uma atividade pessoal $e$ intransmissível, Alarcão e Tavares (2003: 71) alertam para a importância da integração e respeito, no processo supervisivo, da filosofia de ensino do professor, mostrando-se necessário, por vezes, ajudar a torná-la visível e consciente, através do desenvolvimento de atitudes e capacidades de investigação, autorreflexão e autosupervisão crítica. 


\subsection{Estratégias supervisivas: complementaridade para a objetividade}

No que respeita à recolha de informação no processo de supervisão, várias são as estratégias apresentadas pela literatura e experimentadas em práticas supervisivas. A maior ou menor longitude temporal, a sua amplitude de alcance ou o grau de sistematicidade são fatores determinantes na seleção e mobilização da estratégia supervisiva considerada mais adequada.

No quadro de uma supervisão e avaliação de orientação transformadora, cujos princípios, já aqui enunciados, são a indagação e a intervenção crítica e emancipadora, a democratização do exercício do poder de decisão, com base no diálogo entre pares e no respeito mútuo, Vieira e Moreira (2011: 27-60) e Reis (2011: 9) elencam algumas estratégias que podem ser mobilizadas num processo de supervisão: o autoquestionamento/avaliação; o diálogo crítico; a análise documental; o inquérito; o portefólio; as narrativas profissionais; a investigação-ação e a observação de aulas. Contudo, pela maior complexidade e pela maior importância que lhes reconhecem, dão especial destaque às últimas três estratégias.

A literatura é clara no que respeita á necessidade de utilização de várias fontes de informação, pelo que devem ser utilizadas estratégias diversificadas e complementares. Só nestas circunstâncias se poderá construir e formular um juízo avaliativo mais consistente e, por conseguinte, mais justo, porque decorrente de uma visão mais completa e real da ação do professor e do seu desempenho (Reis, 2011: 9). É o caso de Stronge (2010: 24-35), que advoga, como uma das caraterísticas fundamentais de um sistema de avaliação de qualidade, a utilização de múltiplas fontes de recolha de informação para documentar o desempenho, por garantir uma visão mais ampla e mais justa do desempenho.

Independentemente da(s) estratégia(s) utilizada(s), a supervisão deve proporcionar ao professor o desenvolvimento de competências no sentido da construção de percursos autodeterminados e autodirigidos.

No contexto deste trabalho, apenas vamos analisar a observação de aulas, por ser considerada aquela que melhor pode contribuir para a compreensão da ação do professor, centrada no ensino e na aprendizagem e contribuir para a "reconstrução das práticas dos professores" (Vieira \& Moreira, 2011:29).

\subsection{A observação: estratégia privilegiada de recolha de informação sobre o desempenho docente}

Sendo recomendada a recolha de informação através de uma multiplicidade de fontes, como referido no ponto anterior, (Stronge, 2010: 24-43) sublinha que, apesar de apresentar algumas limitações (como a incapacidade de observar várias responsabilidades-chave do professor ou o potencial artificialismo ...), a observação é apresentada como o método mais comum para avaliação de docentes. 
Reis (2011:11), alertando para o facto de se fazer a associação da observação exclusivamente à avaliação e à atividade inspetiva, sublinha o caráter essencialmente formativo que a deve caracterizar, enquanto processo de interação profissional, centrado no desenvolvimento profissional e organizacional e na melhoria das aprendizagens. É nesta medida que a observação se consubstancia como um forte catalisador de mudança na escola. No entanto, este autor lembra ser esta uma estratégia com potencial para ser mobilizada em situações e com finalidades diversas: é o caso da ADD (na qual constitui um ótimo meio de recolha de evidências para tomada de decisões e para um feedback construtivo e/ou a elaboração de planos de melhoria); a aprendizagem através da observação de práticas modelo que proporcionem o contacto com abordagens, metodologias e atividades diversificadas; a partilha e disseminação de práticas com impacto positivo nas aprendizagens dos alunos ou a experimentação de novas abordagens para a resolução de problemas, entre outras.

Deste modo, a observação pode assumir uma tipologia informal ou formal. Em relação à primeira, resultando de observações curtas (15-20 minutos ou 2-3 min) sem pré-aviso ou de conversas regulares entre observador e observado, Reis (2011: 13) apresenta vários modelos (que podem envolver uma equipa de professores observadores e a direção) e lembra que as suas potencialidades passam, entre ouras, pelo reforço da validade do processo (ao permitirem um maior $\mathrm{n}^{0}$ de observações) e da componente formativa, bem como a promoção da reflexão dos professores e uma maior celeridade na deteção e resolução de problemas. No respeitante à observação formal, existindo outros métodos, os autores (Reis, 2011; Vieira, 1993; Vieira, 2009; Vieira et al, 2010; Vieira \& Moreira, 2011) são unânimes em considerar o modelo de supervisão clínica como aquele que reúne mais adeptos e que mais tem influenciado os modelos supervisivos a nível internacional, desde a sua apresentação nos EUA nos anos 60 (importado para Portugal pela mão de Alarcão na década de 80 do séc. XX). Vieira e Moreira (2011:28-29) consideram, ainda, ser este o modelo que, para além de mais ter resistido no tempo, em contexto de ADD, melhores contributos pode dar na observação de aulas e na melhoria das práticas pedagógicas.

Convocando Goldhammer et al. (1980), estas autoras enumeram como características principais deste modelo o facto de: corresponder a um mecanismo que implica uma intervenção deliberada no processo de instrução, no sentido da sua melhoria; ser orientada por finalidades de desenvolvimento pessoal e coletivo; ter como ponto de partida uma relação interpessoal baseada na confiança mútua: compreensão, apoio e comprometimento no processo de desenvolvimento mútuo; ser sistemática, embora flexível e com avaliação/atualização permanente da metodologia; potenciar uma tensão produtiva no sentido de aproximar o real do ideal; pressupor um supervisor com mais experiência e conhecimento do que o observado e implicar a formação do supervisor. 
Este modelo, centrado na observação e análise colaborativa das práticas de ensino e aprendizagem com o objetivo de as melhorar (Vieira \& Moreira, 2011:29) e de modo a promover benefícios mútuos no desenvolvimento pessoal e profissional (Reis, 2011:19), é operacionalizado pela implementação de ciclos constituídos por três fases distintas, mas interligadas: a pré observação, a observação propriamente dita e a pós observação, correspondendo, na opinião de Graça et al (2011: 67), às etapas de preparação, de realização e de reflexão, às quais está subjacente um conjunto de tarefas distintas, mas em interligação e interdependência continuada e cíclica. Neste sentido, e como forma de garantir a análise das situações educativas de forma neutra, objetiva e científica, estas autoras sublinham a importância da construção do projeto de observação (ibid.), o qual surge através da resposta a cinco questões: Observar para quê? O quê? Onde? Como? Quando?

Em conformidade com este modelo crítico de supervisão clínica, encarado como um instrumento de emancipação individual e coletiva dos professores e como uma tarefa a realizar com os professores e não sobre os professores (Angulo, 1999, cit. em Vieira \& Moreira, 2011: 30), o processo supervisivo deve conduzir a uma prática indagatória e reflexiva, através do trabalho colaborativo e de colegialidade. Neste sentido, sublinham as autoras que o ciclo de observação deve assumir como função primordial a problematização de práticas e de possibilidades dentro da dimensão pedagógica.

Assim, o encontro que antecede a observação apresenta-se como fundamental, não só para conhecimento mútuo de observador e observado, mas como preparação da observação, nomeadamente no que respeita a instrumentos de registo, tipo de enfoque e calendarização da observação.

No que respeita à sua operacionalização e aos instrumentos de registo que podem orientar a observação, estes devem ser construídos de acordo com os objetivos definidos. Assim, podem ser utilizadas listas de verificação, escalas de classificação, mapas de registo ou grelhas de observação. Por sua vez, as grelhas de observação podem ser mais ou menos estruturadas e focalizadas, pelo que podem ser utilizadas grelhas de observação de fim aberto (observação global ou naturalista), que permite ao observador registar o maior número de informações, de fim semiaberto (mantem um âmbito amplo de observação, embora centrada mais num aspeto) ou grelhas de observação focada em aspetos mais específicos do comportamento do professor (estratégias de ensino, clareza, organização e gestão, interação, ambiente de sala de aula,...), visando, segundo Reis (2011: 29), uma análise e discussão mais aprofundada do desempenho do professor.

$\mathrm{O}$ encontro posterior à observação de aula é crucial para a consolidação da dimensão formativa e desenvolvimentista do processo, através de um feedback construtivo. Como lembra Reis (2011.53), a análise das informações recolhidas permite que professor e supervisor possam construir significados, identificar os espaços de desenvolvimento e superação das 
dificuldades, bem como definir prioridades para as sessões seguintes. Lembra que são, no entanto, vários os fatores que podem concorrer para a eficácia desta etapa, a saber: o tempo que medeia a observação e reflexão (até 2 dias, para que os dados não percam significado e pertinência e o professor não perca a motivação); o local onde se realiza o encontro (a sala onde foi realizada a observação pode ajudar a reconstruir a aula e a contextualizar o feedback); diálogo/discussão mais profundo entre observado e observador (embora os comentários possam ser escritos); a qualidade do feedbackdeterminante - (deve ser construtivo, com base nos registos).

Numa reflexão sobre os constrangimentos inerentes à observação de aulas em contexto de ADD Vieira e Moreira (2011:38) problematizam a influência da filosofia de ensino do supervisor em todo o processo supervisivo, consubstanciando o caráter subjetivo, nomeadamente na construção do feedback a dar ao professor, em consequência das diversas possibilidades de perceção sobre o mesmo comportamento. Contudo, lembram que outros constrangimentos podem pôr em causa a fiabilidade da observação de aulas enquanto instrumento classificatório, entre os quais salientamos: o mito da objetividade na recolha de informação; a incompetência do observador; os efeitos da sua presença (para alunos e professor); a falta de transparência e negociação quanto a processos e finalidades; a diferença de estatuto entre observador e observado; a fraca regularidade das observações; focalização exclusiva em determinados aspetos.

A mesma problematização é apresentada por Reis (2011: 8-9), que coloca a tónica em três aspetos que considera cruciais e para os quais apresenta resposta: sobre a dificuldade de construção de uma imagem real e completa relativamente às práticas e competências do professor, através das aulas observadas, responde com a necessidade de complementar a observação com outras fontes de informação. No respeitante à possível falta de fiabilidade/representatividade das mesmas em relação ao desempenho característico do professor, o autor considera que, apesar de todas as limitações possíveis, as aulas observadas representam sempre uma mais valia, pela reflexão a que obriga a sua planificação. Relativamente ao constrangimento que decorre da falta de competências supervisivas por parte do observador, Reis considera que o mesmo se ultrapassará, não só com a promoção de formação de professores observadores, mas também com a implementação sistemática destas práticas e a estimulação dos professores para uma atitude mais colaborativa e auto reflexiva.

Neste sentido, e à luz de uma visão formativa e transformadora da supervisão/observação, Vieira e Moreira (2011: 39), chamam a atenção para a extrema cautela na utilização da observação como meio de avaliação sumativa (nomeadamente através da utilização de grelhas demasiado coladas aos parâmetros de $\mathrm{ADD}$ ), preconizando a diversificação das práticas de observação e o recurso a outras fontes de recolha de evidências da qualidade da ação dos professores (materiais e projetos inovadores, reflexões sobre a 
prática, apreciações dos alunos e trabalhos desenvolvidos por estes, ...), como forma de ampliar as suas funções formativas.

\section{PROCESSO DE ADD NA ESCOLA ALFA NO PERÍODO 2009/2011}

\subsection{Reconstituição do processo: aspetos mais relevantes}

Como forma de conhecer o processo de implementação do sistema de ADD nesta escola, foi aplicada uma entrevista a três professores dessa escola que desempenharam as funções de avaliadores. Um deles era Coordenador de Departamento, tendo sido avaliado pelo Diretor. Dos outros dois, avaliados pelos Coordenadores dos respetivos Departamentos, apenas um solicitou observação de aulas. Das informações recolhidas, salientaremos as mais relevantes, relativamente à análise pretendida: (in)conformidade com os modelos teóricos propostos pela literatura e (in)fidelidade aos referentes externos (normativos) e internos (PE).

A comunicação sobre os procedimentos a desenvolver foi dada em Conselho Pedagógico aos Coordenadores de Departamento que, por sua vez a transmitiram à totalidade dos professores. No final do primeiro período foi entregue aos professores um conjunto de informações, entre as quais estavam incluídas as funções da CCAD e a sua constituição, os referentes a ter em conta (internos e externos), os intervenientes no processo, as dimensões e os domínios da avaliação, os documentos de registo de avaliação e a indicação da legislação que regulamentava o processo.

Foi solicitada a reflexão sobre o assunto em Grupo e em Departamento, no sentido da apresentação de sugestões para a elaboração dos instrumentos de avaliação. No entanto estes seriam construídos apenas pela CADD, sem qualquer integração das sugestões apresentadas quer por avaliadores, quer por avaliados.

$\mathrm{Na}$ opinião dos entrevistados os professores avaliadores foram apenas classificadores, uma vez que a supervisão não se desenvolveu enquanto processo formativo, no sentido do desenvolvimento pessoal e profissional. Apenas foi aplicada a grelha de registo de observação, sem qualquer instrução no sentido da supervisão acompanhada dos docentes em avaliação, muito menos foi incluída no processo a preparação da observação (préobservação) nem a formalização da avaliação da mesma (pós-observação). Apenas foram acontecendo conversas informais, decorrentes de encontros ocasionais dos professores avaliadores e avaliados, pelo que se conclui não ter sido desenvolvido o ciclo de observação, considerado pela literatura como fundamental para a prossecução dos objetivos formativos que devem enformar o processo avaliativo.

Relativamente à forma de avaliar cada um dos indicadores constantes nos instrumentos de avaliação, nomeadamente na grelha de observação, foram dadas instruções para que fosse atribuída uma classificação numérica correspondente a cada uma das cinco menções qualitativas, valor esse que 
correspondia à média aritmética dos extremos (máximo e mínimo) legalmente estatuídos para essa menção.

\subsection{Análise crítica: infidelidades referenciais e/ou falta de conhecimentos e de competências supervisivas/avaliativas?}

Aspetos positivos: No processo em análise, parece-nos haver alguns pontos bem intencionados, como se pode aferir da análise das entrevistas.

Em primeiro lugar, referimos a preocupação inicial em informar todos os professores sobre o que era considerado essencial sobre avaliação, nomeadamente a referência à legislação correspondente, bem como a comunicação geral sobre os procedimentos a desenvolver. Por outro lado, a solicitação da colaboração de todos os docentes na construção dos instrumentos de avaliação consubstancia uma conceção positiva, no sentido do envolvimento e do comprometimento de todos, indo ao encontro do preconizado na literatura, como é o caso da trilogia dos $\mathrm{Cs}^{4}$ de Stronge (2010), mas também no cumprimento do estabelecido no respetivo PE, onde se preconiza como prioritário o desenvolvimento de um processo de formação de professores caracterizado por uma atitude reflexiva, colaborativa e de partilha. Contudo, esses contributos não tiveram qualquer repercussão/visibilidade nos instrumentos de avaliação, o que provocou algum esvaziamento do sentido inicial. Ainda assim, parece-nos que, ao promover a reflexão em Departamento e em Grupo Disciplinar, esta estratégia terá consubstanciado um contributo relevante para a tomada de conhecimento do processo de avaliação por parte dos professores da escola em geral.

Pontos fracos: Do nosso ponto de vista, o processo de supervisão através da observação de aulas foi desenvolvido numa perspetiva apenas sumativa, visível pela prevalência da preocupação com a componente numérica. Tal como se pode constatar nas entrevistas, este decorreu de forma pouco coerente com aquilo que é veementemente preconizado pela literatura, mas que está igualmente estatuído nos normativos que regulam o processo (DL $\mathrm{n}^{\circ}$ $75 / 2010$, de 23 de janeiro), considerando entre os objetivos gerais da avaliação o desenvolvimento pessoal e profissional (ponto $1 \mathrm{do} \operatorname{art}^{\circ} 40^{\circ}$ ), nomeadamente através da promoção de um processo de acompanhamento $e$ supervisão da prática docente (alínea h, do ponto 3). Nesta escola não se vislumbra esta preocupação com o desenvolvimento profissional, muito menos o desenvolvimento organizacional, o que configura mais uma infidelidade ao seu PE, onde se considera como crucial a promoção e garantia de formação adequada às necessidades organizacionais, pessoais e profissionais dos professores. A grande preocupação parece ter sido a gestão

\# Comunicação, Colaboração e Compromisso 
do problema criado pela contingentação imposta para cada uma das menções classificativas a atribuir.

Uma das grandes lacunas daí resultantes prende-se com a impossibilidade de identificação de necessidades de formação e/ou supervisão mais regular, por parte de alguns profissionais com mais dificuldades e a correspondente elaboração de um plano de formação que, centrado na escola e a partir das necessidades reais, em muito contribuiria para a desejada melhoria das práticas de ensino e de aprendizagem.

É nossa convicção de que grande parte destes constrangimentos, para além da necessidade de gerir a restrição de vagas para progressão na carreira, passaram pela falta de formação dos supervisores. Também neste aspeto não foi cumprido o objetivo fixado no PE de criar condições para um exercício de funções mais eficaz, através da promoção de formação dos professores com função de avaliadores.

Esta fragilidade pretende-se que venha a ser ultrapassada no próximo ciclo avaliativo, uma vez que a avaliação da componente científica e pedagógica será da responsabilidade de docentes detentores de formação especializada na área da supervisão pedagógica e avaliação docente. Contudo, a exiguidade de aulas a observar - 180 minutos (DR n ${ }^{\circ}$ 26/2012, de 21 de fevereiro, art $^{\circ} 18^{\circ}$, ponto 4 ) - pode limitar de forma significativa esse objetivo de enfoque na dimensão formativa.

Para além dos padrões de desempenho docente estabelecidos a nível nacional, sob proposta do $\operatorname{CCAP}^{\S \S}$ (alínea a do $\operatorname{art}^{\circ} 7^{\circ}$ do DR $n^{\circ} 2 / 2010$, de 23 de janeiro) - referentes externos - o desenvolvimento do processo de avaliação docente deve ter como referentes internos as metas e objetivos fixados no PE e no PAA (id., alínea b). Da análise que fizemos ao PE do Agrupamento a que pertence a Escola Alfa, e como acima assinalado, pode concluir-se que a prática consubstanciou uma grande infidelidade aos mesmos, não chegando a ação onde previa o discurso e a intenção.

\subsection{Conclusão e propostas de melhoria}

Pela análise feita, parece-nos que ficaram subentendidas as nossas propostas de melhoria de todo o processo, de modo a torná-lo mais coerente, robusto e útil.

Em primeiro lugar, a escola deveria ter começado por fazer o levantamento dos professores com formação especializada e chamá-los a colaborar de forma mais próxima. Esta estratégia teria contribuído de forma decisiva para a melhoria do processo, nomeadamente no que diz respeito à adequação dos instrumentos e à potenciação da dimensão formadora do processo de supervisão/observação. Teria também contribuído para a elaboração conjunta de instrumentos de registo/observação, capazes de garantir uma avaliação mais justa e com equidade, tal com estipulado no PE.

${ }^{\S \S}$ Conselho Científico para a Avaliação de professores 
Neste sentido, consideramos fundamental a elaboração de instrumentos de planificação de aulas específicos em cada grupo disciplinar.

Em segundo lugar, consideramos que a preocupação demonstrada inicialmente, pela CCAD e pelo Conselho Pedagógico com a comunicação e informação sobre os procedimentos, deveria ter tido continuidade ao longo de todo o processo, como forma de promover o envolvimento de todos, mas também de garantir maior uniformidade processual, maior transparência, clareza e, consequentemente, maior equidade e utilidade. Na linha de Stronge (2010: 24-43), para além da permanente comunicação bilateral entre avaliador e avaliado, consideramos fundamental a comunicação regular, quer pública, quer a nível individual e particular, nomeadamente por parte da Direção, como forma de dar feedback construtivo e contínuo no sentido de promover a autorregulação da ação por parte dos docentes e de manter a sua confiança no processo de avaliação.

Em terceiro lugar, consideramos fundamental o desenvolvimento do processo de supervisão com objetivos de crescimento profissional, nomeadamente através da regulamentação/implementação das fases preparatória e avaliativa/reflexiva do ciclo de observação. Esta estratégia tornaria possível o acima referido levantamento das necessidades de formação por parte de alguns professores e a elaboração de um plano de formação centrado na escola e, bem assim, capaz de contribuir para a efetiva melhoria das práticas letivas.

\section{REFERÊNCIAS BIBLIOGRÁFICAS}

Alarcão, I e Tavares, J. (2003). Supervisão da Prática Pedagógica. Uma perspetiva de desenvolvimento e aprendizagem. Coleção Ciências da Educação e Pedagogia. Coimbra: Edições Almedina, SA.

Baptista, I. (2011). Ética, Deontologia e Avaliação do Desempenho Docente. Coleção Cadernos do CCAP - 3. Lisboa: Ministério da Educação Conselho Científico para a Avaliação de Professores.

Caetano, A. (2008). Avaliação de desempenho. O essencial que avaliadores e avaliados precisam de saber. Lisboa: Livros Horizonte.

Curado, A. P. (2002). Política de avaliação de professores em Portugal: um estudo de implementação. Textos Universitários de Ciências Sociais e Humanas. Lisboa: Fundação Calouste Gulbenkian, Fundação para a Ciência e Tecnologia e Ministério da Ciência e da Tecnologia.

Fernandes, D. (2008). Avaliação do Desempenho Docente: Desafios, Problemas e Oportunidades. Cacém: texto Editores, Lda.

Flores, M. A. (2010). Avaliação de professores numa perspetiva internacional. Sentidos e implicações. Porto: Areal Editores.

Formosinho, J., Machado, J., Oliveira-Formosinho, J. (2010). Formação, desempenho e avaliação de professores. Mangualde: Edições Pedago. 
Graça, A., Duarte, A., P., Lagartixa, C., Tching, D., Tomás, I., Almeida, J. et al. (2011). Avaliação do Desempenho Docente. Um guia para a ação. Lisboa: Lisboa Editora, S.A.

Leite, C., Pacheco, J., Moreira, E. et al. (1995). Avaliar a avaliação. Cadernos Pedagógicos. Porto: Edições ASA.

Pacheco, J., A. (2009). Para uma sustentabilidade avaliativa do professor. Revista ELO 16 - Maio de 2009, 43-49.

Ramos, C. C. (2007). A Importância da Avaliação do Desempenho de Professores. In, Atas da conferência internacional "Avaliação de Professores. Visões e realidades”, 11-16. Lisboa: Ministério da Educação-CCAP.

Reis, P. (2011). Observação de aulas e Avaliação do Desempenho Docente. Coleção Cadernos do CCAP - 2. Lisboa: Ministério da Educação Conselho Científico para a Avaliação de Professores.

Stronge, J., H. (2010). O que funciona, de facto, na avaliação de professores: breves considerações. In, Flores, Avaliação de professores numa perspetiva internacional. Sentidos e implicações, 21-43. Porto: Areal Editores.

Vieira, F. e Moreira, M., A. (2011). Supervisão e Avaliação do Desempenho Docente. Para uma abordagem de orientação transformadora. Coleção Cadernos do CCAP - 1. Lisboa: Ministério da Educação - Conselho Científico para a Avaliação de Professores.

\section{LEGISLAÇÃO CONSULTADA}

Circular no 367/32, de 11 de Março

Decreto-Lei $n^{\circ} 36$ 507/47, de 17 de Setembro

Lei $n^{\circ} 46 / 86$, de 14 de outubro (LBSE)

Decreto Lei $\mathrm{n}^{\circ}$ 139-A/ 90, de 28 de Abril (1 ${ }^{\circ}$ ECD)

Decreto regulamentar 14/92, de 4 de Julho

Decreto lei $\mathrm{n}^{\circ} 1-98$ de 2 de janeiro ( $1^{\mathrm{a}}$ reformulação ao ECD)

Decreto Regulamentar $11 / 98$, de 15 de maio

Decreto lei $n^{\circ} 15 / 2007$, de 19 de janeiro (2a alteração ao ECD)

Decreto Regulamentar n⿳2/2008, de 10 de janeiro

Decreto Lei no75/2010, de 23de junho

Decreto Regulamentar n'2/2010, de 23 de junho

Decreto Lei n ${ }^{\circ} 41 / 2012$, de 21 de fevereiro ( $11^{\text {a }}$ alteração ao ECD)

Decreto Regulamentar n 26/2012, de 21 de fevereiro 